\title{
Chapter 10 \\ A Commentary: Extending the Research Discourse from Interests and Beliefs to Values
}

\author{
Wee Tiong Seah
}

\begin{abstract}
This commentary unpacks and interprets the various attributes that were examined in the chapters included in this section, that is, interest, motivation, personal meanings, and values. It looks at how they extend and deepen our understanding of the roles played by values and valuing in mathematics education research. It emphasises the opportunity for a re-focus on the purpose of learning mathematics to one of cultivating values and practising valuing, beyond acquisition of mathematical content knowledge and skills.
\end{abstract}

\subsection{Introduction}

This section features a collection of writings which investigate and deepen our understanding of mathematics learning and teaching from the perspectives of interest (Achmetli \& Schukajlow), motivation (Bofah \& Hannula; Middleton, Mangu, \& Lee; Wilkie), personal meanings (Vollstedt \& Duchhardt), values (Dobie), and multiple affective aspects including interest, motivation and value (Zonnefeld). Amongst these variables, values are often perceived to be the most fundamental, most internalised, and most stable (e.g. Bishop, 1988; Roccas, Sagiv, \& Navon, 2017; Stern, 2000), thus guiding the nature, form and activities of one's motivation and attitudes. In this context, this commentary will adopt the values perspective to interpret and summarise the content, with the aim of exploring how the values approach to mathematics education (research) might be enriched further.

W. T. Seah $(\bowtie)$

Melbourne Graduate School of Education, The University of Melbourne, Melbourne, Australia e-mail: wt.seah@unimelb.edu.au 


\subsubsection{Not Just Values, But Also, Values in Mathematics Education}

The 'values' construct is not new in the academic world (e.g. Kluckhohn, 1962), and this commentary will begin with a brief outline of its development. One line of research attention highlights the values that are inherent within the discipline, such as by UNESCO (1979) when it made reference to "the principal criteria which constitute the efficiency of this tool of investigation and communication [that is, mathematics]: intelligibility, brevity, accuracy, relevance, normality" (p. 10). Another direction of research tradition has been concerned with the purposeful and planned teaching of moral and civics values to students (see, for example, Thornberg \& Oğuz, 2013). Yet another research direction has been focussing on the emergence and/or portrayal of some of these values in the process of teaching and learning school subjects such as history, languages, and science (e.g. Allchin, 1999; Hill, 1991).

The construct of values/valuing as it applies to mathematics teaching and learning explicitly has been a relatively recent one, however. It was only in 1996 when Alan Bishop made public his conceptualisation of the categories of values that are espoused in the Western school mathematics classroom, that is, the classroom as a site of intersection amongst mathematical values, mathematics educational values, and general educational values. That took place in a regional mathematics education research conference in Vietnam, however, and thus most members of the Western research communities were introduced to these categories even more recently. In Bishop (2008), he wrote that his "research approach to values and Mathematical thinking has to date been to focus on mathematical values, and on the actions and choices concerning them" (p. 84).

This development in mathematics education above was a follow up to Bishop's (1988) earlier assertion that Western mathematics as a scientific discipline is an expression of a set of three complementary pairs of mathematical values, namely, rationalism and objectism, control and progress, and mystery and openness. These mathematical values would later make up one of the three categories of values in the (Western) mathematics classroom mentioned above. While mathematical values express the nature of (Western) mathematics as a scientific discipline, the category of mathematics educational values would reflect the attributes of mathematics teaching and learning that are deemed important, and are thus expected to be contextualised differently in different cultures. The third category is made up of what Bishop (1996) called general educational values, which refers to the societal and cultural values that are represented and taught through the school education process.

Bishop (1999) sees "values in mathematics education ... [as] the deep affective qualities which education fosters through the school subject of mathematics" (p. 2). DeBellis and Goldin (2006) extended this definition, when they wrote that "values, including ethics and morals, refer to the deep, 'personal truths' or commitments cherished by individuals" (p. 135). This reflects Halstead and Taylor's (2000) definition of values in the wider education scene, in which they regarded values as being the "principles and fundamental convictions which act as general guides to behaviour, 
enduring beliefs about what is worthwhile, ideals for which one strives, standards by which particular beliefs and actions are judged to be good or desirable" (p. 3), thereby differentiating values (that which is important) from beliefs (that which is true). Hill (1991) had proposed this similarly in the field of education in general, when he defined values as being "held by individuals to which they attach special priority or worth, and by which they tend to order their lives" (p. 4).

A consortium of some 21 research teams located in 18 different economies around the world has been collaborating on values-related mathematics education research since 2009. Called 'The Third Wave Project', it has been finetuning its operating definition of values. In the current view,

valuing refers to an individual's embrace of convictions which are considered to be of importance and worth. It provides the individual with the will and grit to maintain any 'I want to' mindset in the learning and teaching of mathematics. In the process, this conative variable shapes the manner in which the individual's reasoning, emotions and actions relating to mathematics pedagogy develop and establish. (Seah, 2018, p. 616)

These perspectives to values in mathematics education share a similar concern and objective, that is, examining what and how particular values would facilitate more effective mathematics learning and/or teaching. This is significant, given the many students around the world who are disengaged with school mathematics when they are as young as 12 years old, and many also do not choose to study the subject at the senior high school levels and beyond. The argument has been that when students, teachers, and other stakeholders value some particular enabling attributes of mathematics pedagogy, such as open-endedness and application, the subscription to these conative variables would provide the individual with the motivation, drive, and perseverance to see a purpose of studying mathematics, and to engage with the subject in school.

In this context, all the seven chapters in this section can be considered to be researching values/valuing to different degrees. In particular, both Dobie and Wilkie's respective studies made use of the values variable in a more direct manner. Dobie's research question was: "What is the relationship between students' personal values and their ideas about the usefulness of mathematics?". The statements in her survey instrument begin with 'It is important to me that ...', which is in line with the definition of values as being the attributes that are regarded as important. On the other hand, although Wilkie asked her participants to write down what wishes they had for mathematics learning, she had also explained that these were the things that mattered-and thus, were of importance and valued - to the students. Participantgenerated phrases such as 'being better at fractions' and 'wanting to make more effort' (see Table 8.1 in Chap. 8) could thus be interpreted as expressing convictions such as fractions and effort respectively.

The chapter written by Vollstedt and Duchhardt is in the same vein. They had used a questionnaire to survey 193 representative 15- to 16-year old students in Germany for their personal meanings towards mathematics. Although personal meanings may not necessarily represent personal valuing, some of the items in the questionnaire were asking the participants to indicate the extent to which they found particular attributes important—and thus, of value—as shown in Table 7.1 in Chap. 7. These 
would include stimulus statements such as "It is important to me that my family can be proud of my mathematics performance" and "It is important to me that at the beginning of mathematics class, the teacher summarizes the previous lesson".

Although Vollstedt and Duchhardt's chapter does not define values, it acknowledges values as a separate construct, while proposing that "a considerable amount of overlap can be assumed between the concepts and no sharp line of division can be drawn". The concepts referred to include personal meanings, and its conceptual overlap with the notion of values is understandable, given that personal meaning has been taken to denote relevance and personal significance, which thus relate to values' association with worth and importance. Vollstedt and Duchhardt also cited other researchers who regarded "meaning as a generating force for the development of values".

The research work of Bishop (1988), DeBellis and Goldin (1997), and Seah (2005) in the areas of values and valuing in mathematics education has been on identifying attributes of mathematics and its pedagogy which are regarded as being important by students or teachers, examining how these attributes promote a sense of engagement, will, and grit amongst learners, and investigating how teachers might subsequently promote the valuing of these enabling attributes to build engagement, will, and grit amongst the students. Yet, it is interesting that none of these researchers had been referred to in all the chapters here. Even Zonnefeld's reference to DeBellis and Goldin (1997) was related to their framework of affective concepts in general, rather than just on the characteristics of values themselves. In fact, the reference against which she had conceptualised values appears to reflect a view of values being a form of interest: "the value component measured students' views regarding the usefulness, relevance, and worth of statistics in their personal and professional life". Also, Dobie's research with personal values drew on Hill's (1991) definition of values in the general sense.

Instead, the expectancy-value theory which had been introduced by Eccles (1993) into educational research was used by Bofah and Hannula, by Achmetli and Schukajlow, as well as by Dobie. While this theory applies to education generally, its power here has been in facilitating a connection between the constructs of values and motivation, as can be seen in these chapters.

\subsubsection{Valuing Mathematics and Valuing Attributes of Mathematics}

There are two aspects to values and valuing in mathematics education. One is concerned with valuing mathematics, that is, an individual regarding the discipline as important. The other aspect operates independently of the first one, and is concerned with an individual having convictions with particular attributes of the discipline and/or its pedagogy.

Two studies in this section exemplify the first aspect. In one, Zonnefeld's teaching of growth mindset to undergraduates over a period of 12 months resulted in the female 
students valuing statistics much more than their male peers and also performing better than their male peers. This suggests a very significant relationship amongst the variables of values, gender, and performance. That this is in favour of female students further validates the importance of working with the notion of values, in terms of how this approach to mathematics education may empower female students' self-efficacy or confidence in being successful in understanding and performing in mathematics at school. In the other study, Bofah and Hannula's analysis of the 2011 Trends in International Mathematics and Science Study [TIMSS] data (Thomson, Hillman, \& Wernert, 2012) for five African countries included an assessment of students' valuing of mathematics. Importantly, the study found that amongst the various factors analysed, "the association between perceived social support and achievement is accounted for entirely or partly by how the students value and like mathematics". It needs to be mentioned, though, that Bofah and Hannula's notion of mathematics valuing was as a motivational belief in the tradition of the expectancy-value theory, and thus it has some utility flavour.

Individuals' valuing of attributes of mathematics and/or its pedagogy is also evident in this section. In Middleton, Mangu, and Lee's analysis of the responses of some 24,000 United States students when they were in the 9th grade and then when they were in the 11th grade two years later, one of the motivation scales was 'effort'. Here, the extent to which a student emphasises the role of effort in studying mathematics may be regarded as an expression of his/her mathematics educational value, that is, a value that is concerned with an aspect of the process of learning mathematics (Bishop, 1996). In this study, "effort, interestingly decreased across all [four] categories of students, and was especially low for" the group of students who did not intend to pursue a STEM career, and for the group of students who had the intention in the 9 th grade but no longer so two year later.

\subsubsection{The Relevance of Values to Contemporary Mathematics Curriculum Reforms}

An emerging trend of mathematics reforms in recent years has actually brought to the spotlight the significance of researching values. The publication of the 'Principles and Standards for School Mathematics' in 2000 by the National Council of Teachers of Mathematics [NCTM] in the United States had seen the introduction of five process standards alongside the usual content topics. These process standards represent the different ways through which content knowledge might be acquired and applied, and teachers are expected to foster these skills amongst their students. The five NCTM process standards are, namely, problem solving, connections, communication, representations, and reasoning and proof. This curriculum approach of a dual focus on content knowledge and process skills has since been a feature of many an education reforms across the world, such as in Australia, mainland China, Denmark, and Germany. In Australia, the national mathematics curriculum (Aus- 
tralian Curriculum, Assessment and Reporting Authority, 2016) requires schools to teach four identified 'proficiencies strands', namely understanding, fluency, problem solving, and reasoning. The point here is that whether they are called process standards, proficiency strands, or something else, these mathematics learning skills which are being emphasised in contemporary mathematics curricula are considered to be important in relation to learning mathematics well and effectively. That is to say, the Australian mathematics curriculum is requiring teachers to teach students to value understanding, fluency, problem solving, and reasoning at the same time that they are teaching the number line, decimals, symmetry, quadratic equations or probability.

This focus on teaching values at the intended curriculum and beyond is only too timely as we approach a time in human history when artificial intelligence and automation are redefining fundamental job skills in national economies around the world. Acknowledging that we will never be as skilful and efficient as robots and computers at computations and mathematical processing at the workplace an in daily life, (mathematics) education has the responsibility to prepare our next generations to stay relevant and to contribute to the emerging workforce and daily living needs. If soft skills such as teamwork and inclusivity are needed to complement the hard skills which machines and robots excel at, this is where mathematics education can be useful for 'robot-proofing' the human workforce. As should be evident now, these soft skills are also the values which can be nurtured through mathematics. To the extent that such attributes are already being introduced to students through mathematics lessons, we need to understand better how their teaching might be planned deliberately, and/or how it might be executed during class lessons.

\subsection{Comparing Results}

How do the findings represented in this section compare with those derived from related research conducted elsewhere? Wilkie's findings with regards to what upper primary and junior secondary school students in Australia wish for in mathematics learning resonates with the 'What I Find Important (in my mathematics learning)' [WIFI] study which was conducted in economies such as Australia, Hong Kong, Japan, Korea, Macau, Shanghai, and Taiwan in the first half of the 2010s (see Seah \& Wong, 2012). For example, in both Wilkie's study and Kinone, Shinno, and Baba (2013), the valuing of students in the middle years of schooling was found to be different from what students in the senior secondary school years valued, suggesting that different values are associated with different mathematics topics and different cognitive demands while some other values stay the same. Of course, there is also the possibility that during these teenage years, the child's values system is still being consolidated in what Morris Massey (1979) calls the socialisation stage of human values formation.

In another WIFI report, Zhang, Barkatsas, Law, Leu, Seah, and Wong (2016) analysed data collected from 1386 Grades 5/6 students studying in Wuhan (a Chinese 
city), Hong Kong, and Taiwan. The analysed data suggested that these students were valuing achievement, relevance, practice, communication, ICT, and feedback in their respective mathematics learning experiences. Similar between this study and Wilkie's is the positive tone of the values expressed. What is different, however, is that while the Australian students' values were mainly reflective of mastery approaches to goals (as interpreted by Wilkie), there was a balanced mix of mastery and of performance approaches to goal orientations from the students in the three East Asian economies which top such international comparative tests as TIMSS and PISA. Admittedly, neither of these studies were designed to identify if the nature of a student's value is reflective of mastery or performance goal orientations. As such, the research methods used were not designed to determine if East Asian students' valuing of achievement reflect either mastery or performance goal orientation. Yet, the possibility of such a difference in student values between East Asia and Australia may provide another perspective to an understanding of the difference in mathematics performance between East Asia and elsewhere in the world.

Wilkie's data also echoes Grootenboer and Marshman's (2016) findings with New Zealand middle school students, in that fluency with multiplication facts-emphasising the valuing of basic facts — was highly valued amongst the Australian student participants.

One of the findings of Achmetli and Schukajlow's study has been that students' experience with constructing multiple solutions to mathematical problems did not bring about any increase in students' interest in mathematics. This is somewhat surprising, especially given that many researchers (e.g. McLeod, 1992) have conceptualised interest as being easier to manipulate when compared to other affective variables such as beliefs and attitudes.

\subsubsection{Values Alignment}

While both Dobie and Wilkie's studies are more directly related to values in mathematics education, it is also interesting to note that each of them advocates for teacher alignment of student values in their practice. Wilkie ended her chapter by calling for teachers 'to find ways to incorporate students' own suggestions for promoting their engagement, learning, and achievement", which may not be easy to accomplish if what the students value individually represent a wide spectrum of attributes when considered as a class. Some of these values may be in conflict with one another too. On the other hand, Dobie's view was that "teachers can also work to increase alignment with students' values in the classroom". Indeed, values alignment by the classroom teacher is currently being investigated in a follow-up to the WIFI study, called WIFItoo, in Australia. The assumption has been that

values alignment should be regarded as already being part of day-to-day interactions. When individuals come together with their own value systems, they will always need to negotiate about different preferences and intentions to ensure that the interaction is successful. This calls for values alignment to take place, and it does not mean that one party needs necessarily 
to impose his/her/their values to the rest. There can always be middle-path compromises, for example. (Seah, 2018, p. 575)

After all, "all relationships ... are claimed to be strengthened by aligned values" (Branson, 2008, p. 381). How this alignment might be achieved, however, is not yet known, and the WIFItoo study aims to document the various ways in which teachers and their students co-construct values alignment such that productive teaching and learning can take place.

\subsubsection{Values Intervention Programs for Mathematics Classes}

Perhaps reflecting the newness of this research area, the studies in this section-and indeed, in several instances elsewhere as well—are not directly associated with the implementation of values-related intervention programs or education initiatives. Zonnefeld's study, however, is worthy of mention here. In fostering undergraduate classroom environments that support the development of the incremental view of mathematics, a range of affective variables were assessed for changes. At the end of the experimental period, an increase of students' valuing was only one of two statistically significant changes that took place. That female students' valuing increased more than that of their male peers "is a significant finding given the historical underrepresentation of women in mathematics and STEM in general".

Values were also not intentionally examined in the longitudinal study conducted by Middleton, Mangu, and Lee, although student's valuing of effort was evaluated in the study. Over a two-year period, changes in motivation indicators such as identity, interest, and self-efficacy had contributed to volatile changes in students' intention to pursue STEM programs beyond Year 11: "Relatively short-term motivations appear to greatly impact career aspirations. An effort should be made to make STEM curricula continuously attractive in new ways throughout a student's high school education, given the volatility of STEM career intentions". The stability (over two years in this study) of the students' valuing of effort when compared to the other scales surveyed, reinforces the conception that values are very internalised within an individual (see, for examples, Bishop, 1996; Stern, 2000). There are certainly implications here for the mathematics education (research) communities to explore more deeply how the variable of values might be used as a more reliable indicator or predictor of individuals' intentions, decisions, and/or actions in the process of teaching or learning mathematics. 


\subsubsection{Research Methodological Concerns}

As mentioned earlier, amongst the seven studies represented in this section, three might be considered to be researching values, while two other studies dealt with the valuing of mathematics and statistics. The remaining two focused on affective variables such as interest. All seven studies sourced their data from participants who were either in secondary schools or universities. There was no suggestion in the chapters why there was no primary school participant, though it may be argued that for variables such as values which are normally inferred from participant opinions rather than being presented explicitly through actions, a certain level of participant maturity and confidence is needed.

Indeed, the questionnaire method was evident in all the seven chapters, with five of these utilising the questionnaire as the only data source. Accordingly, five of the studies are purely quantitative, although this does not correspond to the five studies which had made use of the questionnaire method only. Wilkie's open-ended questionnaires were analysed qualitatively, for example. At the same time, Dobie had employed mixed methods to analyse her data which were collected through questionnaires, lesson observations, and interviews.

Amongst the studies represented in this section, conclusions about teacher and student valuing appear to be made through analyses of questionnaire responses, except in the case of Dobie's work in which lesson observations provided an additional source of information about the extent to which the students valued the usefulness of mathematics. The valuing of particular attributes, however, needs not necessarily be followed by actions which reflect this valuing. Competing values (see Seah, 2005) may lead to some values being suppressed by other values that are also subscribed to but are more dominant in an individual. Both Halstead and Taylor's (2000) view of values as being general guides to behaviour, and Hill's (1991) tentativeness when writing about values ordering our lives, allow for the competing values narrative.

Perhaps not surprisingly, amongst the chapters in this section, there is a dominance of research that were conducted in Western economies. Of the seven chapters, three were written by researchers based in the USA reporting on American research, two were from Germany, and one from Australia. Even though the remaining non-Western study, conducted by Bofah and Hannula, might be focussed on African nations, the researching was a secondary analysis of TIMSS data and conducted outside Africa. This form of documentation hides the fact that at the international congress whose presentations stimulated the production of this monograph, there were several other research presentations conducted by non-Western researchers and/or conducted in non-Western sites, such as Elizar (Indonesia); Atinuke and Juwe (Nigeria); Felix (South Africa); and Gun \& Bulut and Haser, (Turkey) (Hannula, Morselli, Erktin, Vollstedt, \& Zhang, 2017). Unfortunately, for various practical reasons, these studies are not represented here. This phenomenon is not unique to this event, of course. If we also consider the amount of related research which have been published in nonEnglish language publications, it is easy to imagine that what we get to access from English-language books, reports, journals and magazines constitute only a small 
part of what we collectively know and understand. This is unfortunate, given that the constructs of values and beliefs are highly contextualised in the diverse cultures globally within which they are internalised, activated, and espoused. There are certainly implications as we grapple with the optimisation of the school mathematics learning experiences for refugees, migrants and expatriate children around the world. There is thus a rather urgent need for the international mathematics education community to come together, to collaborate on possible solutions to this issue. In this regard, the kind of cooperation we see in Bofah and Hannula's research and writing is worthy of further exploration by colleagues worldwide. Another potential solution strategy might be for Western researchers to base their academic activities in targeted non-Western cultures, so that there are opportunities for sustained understanding, discussion and reflections by all parties involved.

Thus, from the values perspective, this section has pushed the boundaries of academic knowledge in the field a great deal. The various chapters have reinforced the notion of values as something that is perceived to be of importance and worth (in facilitating mathematics pedagogy). In addition to Bishop's (1996) categorisation of values in the mathematics classroom into mathematical, mathematics educational, and general educational, two of the studies represented in this section suggest that these valuing might manifest as a general valuing of the subject. Values' role in regulating the stability of affective variables such as interest is also suggested by a study here. More practically, what need to be valued by a mathematics student does not have to be the same across grade levels, education systems, and cultures. It might be a case of different values being associated with different mathematics topics and different cognitive demands, while some other values stay the same across the grade levels. It may also be reflecting the experience of a teenager going through values formation. It is also probably unique that students in Australia and New Zealand value basic facts highly. The significant role of values alignment has also been reinforced through the studies represented in this section.

The deeper understanding that is gained through the findings of the studies represented in this section could not have come at a more appropriate time, as the world is witnessing a fast transformation to hybrid intelligence and automation at work and in daily life, which seems to threaten the relevance of learning mathematics at school. A re-focus of the purpose of learning mathematics to one of cultivating values and practising valuing to complement what robots do might just be what is needed to bring about engagement and interest in mathematics amongst students.

\section{References}

Allchin, D. (1999). Values in science: An educational perspective. Science \& Education, 8, 1-12.

Australian Curriculum Assessment and Reporting Authority (ACARA). (2016). The Australian Curriculum: F-10 Mathematics. Sydney, Australia: ACARA.

Bishop, A. J. (1988). Mathematical enculturation: A cultural perspective on mathematics education. Dordrecht, The Netherlands: Kluwer. 
Bishop, A. J. (1996, June 3-7). How should mathematics teaching in modern societies relate to cultural values-Some preliminary questions. Paper presented at the Seventh Southeast Asian Conference on Mathematics Education, Hanoi, Vietnam.

Bishop, A. J. (1999). Mathematics teaching and values education: An intersection in need of research. Zentralblatt fuer Didaktik der Mathematik, 31(1), 1-4.

Bishop, A. (2008). Teachers' mathematical values for developing mathematical thinking in classrooms: Theory, research and policy. The Mathematics Educator, 11(1/2), 79-88.

Branson, C. M. (2008). Achieving organisational change through values alignment. Journal of Educational Administration, 46(3), 376-395.

DeBellis, V. A., \& Goldin, G. A. (1997). The affective domain in mathematical problem solving. In E. Pehkonen (Ed.), Proceedings of the 21st conference of the International Group for the Psychology of Mathematics Education (Vol. 2, pp. 209-216). Lahti, Finland: PME.

DeBellis, V. A., \& Goldin, G. A. (2006). Affect and meta-affect in mathematical problem solving: A representational perspective. Educational Studies in Mathematics, 63(2), 131-147.

Eccles, J. S. (1993). School and family effects on the ontogeny of children's interests, selfperceptions, and activity choices. In J. Jacobs (Ed.), Nebraska symposium on motivation: Developmental perspectives on motivation (pp. 145-208). Lincoln, NE: University of Nebraska Press.

Grootenboer, P., \& Marshman, M. (2016). Mathematics, affect and learning: Middle school students' beliefs and attitudes about mathematics education. Singapore: Springer.

Hannula, M., Morselli, F., Erktin, E., Vollstedt, M., \& Zhang, Q. P. (2017). Topic Study Group No. 28: Affect, beliefs and identity in mathematics education. In Proceedings of the 13th International Congress on Mathematical Education (pp. 507-510). Cham, Switzerland: Springer.

Halstead, J. M., \& Taylor, M. J. (2000). The development of values, attitudes and personal qualities: A review of recent research. Slough, UK: National Foundation for Educational Research.

Hill, B. V. (1991). Values education in Australian schools. Melbourne, Australia: The Australian Council for Educational Research.

Kinone, C., Shinno, Y., \& Baba, T. (2013). International comparative study 'The Third Wave' regarding values in mathematics education (2): Factor analysis on Japanese students' values in learning mathematics. Research Journal of Mathematical Education, 95, 105-112.

Kluckhohn, C. (1962). Values and value-orientations in the theory of action: An exploration in definition and classification. In T. Parsons \& E. A. Shils (Eds.), Toward a general theory of action (pp. 388-433). New York, NY: Harper \& Row.

Massey, M. E. (1979). The people puzzle: Understanding yourself and others. Englewood Cliffs, NJ: Brady.

McLeod, D. B. (1992). Research on affect in mathematics education: A reconceptualisation. In D. A. Grouws (Ed.), Handbook of research on mathematics teaching and learning (pp. 575-596). Reston, VA: National Council of Teachers of Mathematics.

Roccas, S., Sagiv, L., \& Navon, M. (2017). Methodological issues in studying personal values. In S. Roccas \& L. Sagiv (Eds.), Values and behavior: Taking a cross cultural perspective (pp. 15-50). Cham, Switzerland: Springer.

Seah, W. T. (2005). The negotiation of perceived value differences by immigrant teachers of mathematics in Australia. (Ph.D. dissertation). Monash University, Victoria, Australia.

Seah, W. T. (2018). Improving mathematics pedagogy through student/teacher valuing: Lessons from five continents. In G. Kaiser, H. Forgasz, M. Graven, A. Kuzniak, E. Simmt, \& B. Xu (Eds.), Invited Lectures from the 13th International Congress on Mathematical Education (pp. 561-580). Cham, Switzerland: Springer.

Seah, W. T., \& Wong, N. Y. (2012). What students value in effective mathematics learning: A 'Third Wave Project' research study. ZDM: The International Journal on Mathematics Education, 44, 33-43. https://doi.org/10.1007/s11858-012-0391-4.

Stern, P. C. (2000). Toward a coherent theory of environmentally significant behaviour. Journal of Social Issues, 56(3), 407-424. 
Thomson, S., Hillman, K., \& Wernert, N. (2012). Monitoring Australian Year 8 student achievement internationally: TIMSS 2011. Victoria, Australia: Australian Council for Educational Research. Retrieved from http://research.acer.edu.au/timss_pirls_2011/1/.

Thornberg, R., \& Oğuz, E. (2013). Teachers' views on values education: A qualitative study in Sweden and Turkey. International Journal of Educational Research, 59(1), 49-56.

UNESCO. (1979). New trends in mathematics teaching (Vol. IV). Paris, France: UNESCO.

Zhang, Q., Barkatsas, T., Law, H. Y., Leu, Y.-C., Seah, W. T., \& Wong, N.-Y. (2016). What primary students in the Chinese Mainland, Hong Kong and Taiwan value in mathematics learning: A comparative analysis. International Journal of Science and Mathematics Education, 14(5), 907-924.

Open Access This chapter is licensed under the terms of the Creative Commons Attribution 4.0 International License (http://creativecommons.org/licenses/by/4.0/), which permits use, sharing, adaptation, distribution and reproduction in any medium or format, as long as you give appropriate credit to the original author(s) and the source, provide a link to the Creative Commons license and indicate if changes were made.

The images or other third party material in this chapter are included in the chapter's Creative Commons license, unless indicated otherwise in a credit line to the material. If material is not included in the chapter's Creative Commons license and your intended use is not permitted by statutory regulation or exceeds the permitted use, you will need to obtain permission directly from the copyright holder. 